\title{
THE PROTEOLYTIC ACTIVITY OF PSEUDOMONAS FLUORESCENS 07A ISOLATED FROM MILK IS NOT REGULATED BY QUORUM SENSING SIGNALS
}

\author{
Uelinton M. Pinto ${ }^{1}$; Esther D. Costa $^{1}$; Hilario C. Mantovani ${ }^{2}$; M.C.D. Vanetti ${ }^{2}$
}

\author{
${ }^{1} 363$ Wing Hall, Department of Microbiology, Cornell University, Ithaca NY, USA; ${ }^{2}$ Departamento de Microbiologia, \\ Universidade Federal de Viçosa, Viçosa, MG, Brasil.
}

Submitted: September 23, 2008; Returned to authors for corrections: March 30, 2009; Approved: August 22, 2009.

\begin{abstract}
The proteolytic activity of Pseudomonas fluorescens 07A was investigated, and was optimal on tryptone-calcium medium. N-acyl-homoserine lactones (AHLs) were not detected on supernatants of late-exponential and stationary-phase culture broths. Synthetic AHLs or bacterial cell extracts added to the medium did not influence growth or proteolytic activity suggesting that quorum sensing might not regulate protease production in this strain.
\end{abstract}

Key words: Pseudomonas fluorescens, proteolytic activity, quorum sensing.

Product contamination with psychrotrophic microorganisms is of particular concern for the dairy industry because dairy products are distributed at temperatures favorable for their growth (4). Pseudomonas, particularly $P$. fluorescens, is frequently isolated from refrigerated raw milk and associated with proteolysis and lipolysis (11, 14, 23). Although proteolytic activity of this specie has been detected at the end of the logarithmic phase of growth $(11,14)$ little is known about the involvement of cell density in the regulation of protease production in Pseudomonas isolated from milk and other food products.

Many gram-negative bacteria coordinate gene expression according to cell density (26), in a mechanism termed quorum sensing (QS). QS usually relies on the production of diffusible signals known as N-acyl homoserine lactones (AHLs) (26). Research on QS has mainly focused on the model bacterium Vibrio fisheri, and strains of medical or agricultural significance such as Pseudomonas aeruginosa, Vibrio cholerae and Agrobacterium tumefaciens. Some previous works indicated that many bacterial species commonly found in food produce AHLs $(5,6,17,19,22)$, but the role of QS in food deterioration is not evident. The understanding of the role of cell-cell communication in the regulation of food spoilage phenotypes may be useful in developing new strategies to control food deterioration.

Previously, it was shown that $P$. fluorescens 07A, a strain isolated from milk, contains an apr homologue which encodes for an extracellular metalloprotease (13). Thus, this bacterium has the potential to produce proteases that spoil milk. In another study it was also shown that this strain was able to induce A. tumefaciens A136 bioassay strain for AHL detection, a first indication of AHL production (17). The aim of the present study was to investigate the proteolytic activity of $P$. fluorescens strain 07A isolated from milk and to test if protease production in this strain is associated with QS.

$P$. fluorescens $07 \mathrm{~A}$ was cultivated at $22^{\circ} \mathrm{C}$, with agitation 
of $150 \mathrm{rev} \mathrm{min}^{-1}$ in Tryptone Yeast Extract Phosphate (TYEP) medium (11), supplemented with $0.25 \%$ of $\mathrm{CaCl}_{2}$, or $0.5 \%$ of lactose, or $0.5 \%$ of glucose; or in minimal salt medium (MSM) containing $\mathrm{CaCl}_{2}$ at $1 \mathrm{mmol} \mathrm{l}^{-1}$ (9); or in skin milk $12 \%$. A. tumefaciens bioassay strain KYC55 (pJZ410) (pJZ372) (pJZ384) was cultivated in A. tumefaciens (AT) medium supplemented with appropriate antibiotics (27). Bacterial growth was monitored by the drop plate method (16). Proteolytic activity was measured by a colorimetric assay (wavelength of $366 \mathrm{~nm}$ ) using azocasein as substrate, according to Rajmohan et al. (18). One unit of proteolytic activity was defined as the amount of enzyme that produced an increase of 0.01 absorbance units at $366 \mathrm{~nm}$ per hour of incubation. Specific proteolytic activity was defined as the unit of enzyme activity multiplied by the factor $10^{10}$ divided by the number of cells.

AHL was extracted from supernatants obtained from $P$. fluorescens 07A cultivated on the above media with ethyl acetate (20). Extracts were added to AT medium containing the AHL monitor strain A. tumefaciens KYC55 and tested for $\beta$ galactosidase activity (15). To further characterize the potential signals produced by strain $07 \mathrm{~A}$, bacterial extracts obtained by ethyl acetate treatment as described above were spotted in volumes of $20 \mu$ l onto C18 reversed-phase Thin Layer Chromatography (TLC) plates (Partisil LKC18, Whatman cat\#4800800). N-3-oxo-octanoyl-HSL (OOHL) was used as a positive control. The chromatogram was developed and revealed as described by Shaw and collaborators (20). Extracts obtained from bacteria grown on MSM were also analysed for AHL or diketopiperazine using gas chromatography/mass spectrophotometer (Hewlett-Packard 5890 GC/MS).

Furthermore, synthetic AHL and bacterial extracts were added to the growth medium (TYEP $+\mathrm{CaCl}_{2}$ ) in order to test their effect on $P$. fluorescens 07A growth and proteolytic activity. The synthetic AHLs added to the growth medium were alpha-amino butyryl lactone (ABL) or hexanoylhomoserine lactone (HHL) in the concentration and conditions described by Whan and collaborators (25).
Finally, volumes of $250 \mu \mathrm{l}$ of bacterial extracts obtained by ethyl acetate treatment were prepared and added to $2.5 \mathrm{ml}$ of TYEP $+\mathrm{CaCl}_{2}$ inoculated with washed cells of strain $07 \mathrm{~A}$ in

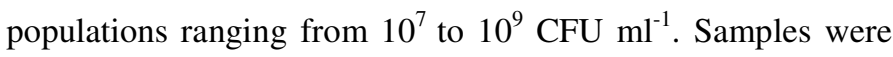
collected at different times for cell number and proteolytic activity determination. As a control, an extract prepared from an equal volume of sterilized medium was added to the culture. Experiments were independently repeated three times.

The highest proteolytic activity levels, as determined by a colorimetric assay (18) were detected on TYEP medium supplemented with calcium (Table 1). When cultures reached early stationary phase of growth $(24 \mathrm{~h}$ to $34 \mathrm{~h}$ incubation in all rich media, and $60 \mathrm{~h}$ in MSM), the specific proteolytic activity of cells grown on TYEP $+\mathrm{CaCl}_{2}$ was twofold higher than those grown on other media (Table 1). An interesting finding is that protease production was detected on MMS at lower celldensities. This study confirms that protease activity is dependent on the growth media and is optimal in media containing calcium, which is in agreement with previous works $(9,11,18)$. Based on these results, TYEP $+\mathrm{CaCl}_{2}$ and MSM, which would present minimal interference on extraction assays for AHL detection, were chosen for subsequent experiments.

The extracts from both media (TYEP $+\mathrm{CaCl}_{2}$ and MSM) activated the bioassay strain, but cell number and activation values (Miller Units) were higher in complex media (results not shown). This result, although preliminary, indicates that the growth media influenced the production of the potential signal molecules by $P$. fluorescens $07 \mathrm{~A}$.

However, TLC analysis revealed that extracts prepared from un-inoculated TYEP $+\mathrm{CaCl}_{2}$ medium produced spots similar to those from 07A strain grown on this medium indicating that quorum sensing unrelated compounds activate the biosensor strain (Fig. 1A). On the other hand, extracts prepared from un-inoculated MMS did not activate the biosensor. Furthermore, no AHL or diketopiperazine molecules were detected by Gas Chromatography/Mass Spectroscopy (GC/MS) analyses of the bacterial extracts. Taken together these results indicate that P. fluorescens 07A 
does not produce AHLS and compounds extracted from the medium and therefore unrelated to QS can activate the bioassay strain, giving rise to false positive results. It has been reported that non-AHL substances can activate biosensors (7), emphasizing that AHL detection should be confirmed by additional methods such as TLC and GC/MS analyses. Martins (12) constructed a trans-conjugant strain of P. fluorescens 07A expressing the aiiA gene which codes for an enzyme that inactivates AHLs. No difference was observed between the trans-conjugant and the wild type strain in a TLC assay for AHL detection. The results of that work (12) also suggest that $P$. fluorescens 07A does not produce AHLs and are in agreement with the present work.

We then tested whether synthetic AHLs (ABL and HHL) had any effect on $P$. fluorescens $07 \mathrm{~A}$ growth and proteolytic activity. The addition of these signal molecules to the growth medium did not affect the growth rate, cell number or proteolytic activity of $P$. fluorescens 07A (Figure 1B). However, activity of extracellular proteases was only detected when cell concentration was higher than $10^{8} \mathrm{CFU} \mathrm{ml}^{-1}$. This indicates that protease activity could be related to cell density, but it does not correlate with AHL presence.

Finally, bacterial extracts obtained by ethyl acetate treatment were prepared and added to TYEP $+\mathrm{CaCl}_{2}$ inoculated with 07A strain. The rationale for this assay is that if P. fluorescens 07A produces extracellular signals able to stimulate protease production, extracts prepared from stationary phase cultures would induce an increment in the proteolytic activity when supplemented to the medium. However, no increase in the level of proteolytic activity of the cell was observed when compared to the control for every population tested (Fig. 1C). This indicates that compounds extracted from $P$. fluorescens 07A by ethyl acetate treatment do not influence the proteolytic activity of the cell. Previous studies attempted to demonstrate the effect of AHL on other $P$. fluorescens strains $(1,8,10,25)$. Addition of $\mathrm{AHL}$ to the medium accelerated biofilm formation by P. fluorescens B52 (1) and reduced the lag phase duration and exponential growth rate (25). Liu et al. (10) verified that a strain of $P$. fluorescens produced AHL, and the transcription regulation of the protease gene $\operatorname{aprX}$ was slightly down-regulated in an AHL deficient strain. In P. fluorescens CHA0, the expression of aprA gene coding for the major protease was positively regulated by the two component system GacS/GacA and showed cell densitydependent expression (21), though the signal molecule was not identified.

Table 1. Cell number, expressed as $\log _{10}$ of Colony Forming Units and specific proteolytic activity (in parenthesis) of $P$. fluorescens $07 \mathrm{~A}$ on different media.

\begin{tabular}{lllllll}
\hline Time (h) & TYEP & TYEP+Lactose & TYEP+CaCl $_{\mathbf{2}}$ & TYEP+Glucose & MSM & Skin Milk \\
\hline 0 & $4.3(0)^{*}$ & $4.3(0)$ & $4.3(0)$ & $4.1(0)$ & $4.4(0)$ & $4.3(0)$ \\
9 & $5.7(0)$ & $5.9(0)$ & $5.8(0)$ & $6.0(0)$ & $5.2(0)$ & $5.7(0)$ \\
13 & $6.9(0)$ & $7.0(0)$ & $7.0(0)$ & $7.4(0)$ & $5.6(0)$ & $6.2(0)$ \\
17 & $8.2(1)$ & $8.3(1)$ & $8.1(1)$ & $8.0(1)$ & $5.7(0)$ & $7.4(1)$ \\
20 & $9.2(13)$ & $9.2(11)$ & $9.2(21)$ & $8.8(09)$ & $6.1(0)$ & $8.0(1)$ \\
24 & $9.3(27)$ & $9.2(32)$ & $9.4(42)$ & $9.0(23)$ & $6.7(1)$ & $8.7(12)$ \\
34 & $9.5(32)$ & $9.2(32)$ & $9.3(62)$ & $9.4(38)$ & $7.4(3)$ & $9.2(40)$ \\
60 & $9.4(28)$ & $9.7(30)$ & $9.8(61)$ & $9.8(32)$ & $8.8(37)$ & $9.8(48)$ \\
80 & $9.1(26)$ & $9.1(25)$ & $9.7(58)$ & $9.8(41)$ & $9.3(32)$ & $9.6(54)$ \\
\hline
\end{tabular}

\footnotetext{
* All means represent average of replicates.
}

Specific proteolytic activity was defined as the unit of enzyme activity divided by the number of cells $\mathrm{x}$ factor $10^{10}$. 
Pinto, U.M. et al.

A)

\section{$\begin{array}{lllll}1 & 2 & 3 & 4 & 5\end{array}$}

C)

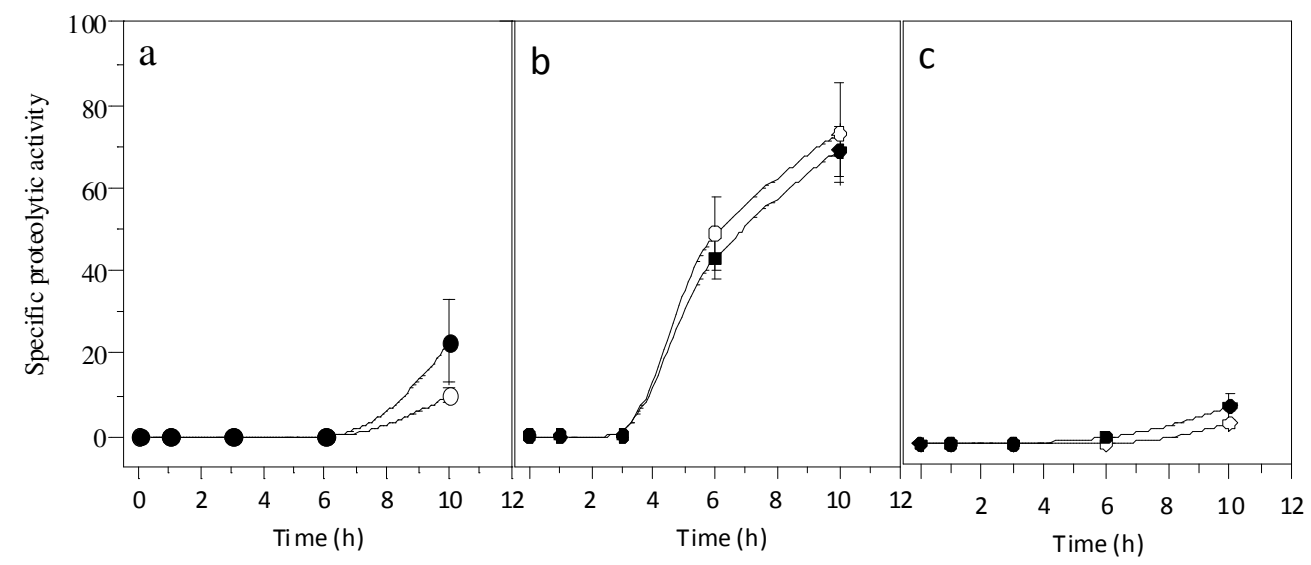

B)

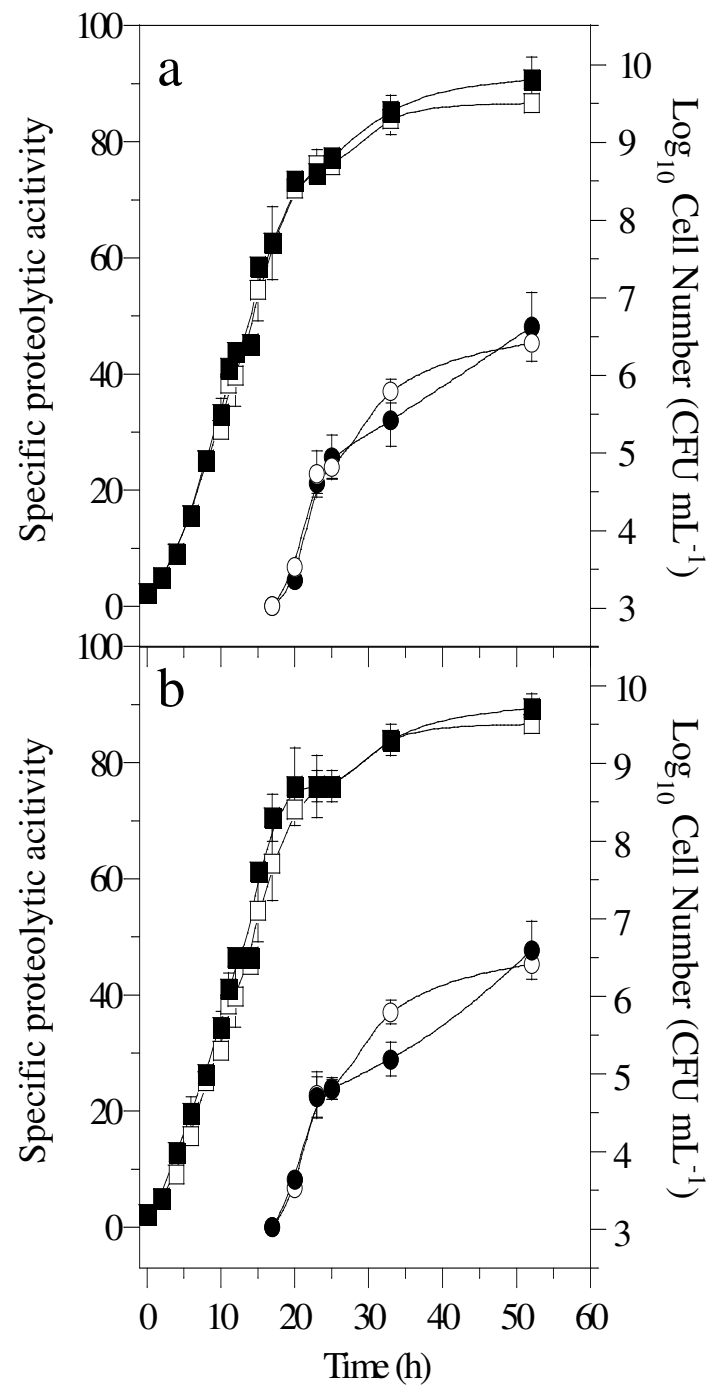

Figure 1. A) Representative TLC assay using KYC55 overlay (17). Lanes contain standard of N-3-oxo-octanoyl-HSL(1), extract of un-inoculated MSM (2) or uninoculated TYEP $+\mathrm{CaCl}_{2}$ (3), and culture extracts of 07A strain grown in TYEP + $\mathrm{CaCl}_{2}$ in early (4) or late exponential growth phase (5).

B) Effect of ABL (5 $\mu \mathrm{g} \mathrm{ml}^{-1}$, part a) and HHL (7.5 $\mu \mathrm{g} \mathrm{ml}^{-1}$, part b) on growth (closed squares) and proteolytic activity (closed circles) of $P$. fluorescens 07A cultivated in TYEP $+\mathrm{CaCl}_{2}$ medium at $22^{\circ} \mathrm{C}$ and $150 \mathrm{rev} \mathrm{min}^{-1}$. The growth (open squares) and proteolytic activity (open circles) of cultures that were not added with the synthetic signal molecules are also shown. The means represent two independent experiments that were performed in duplicate.

C) Effect of the addition of stationary phase bacterial extracts from $P$. fluorescens 07A on the specific proteolytic activity of standardized cell suspensions in TYEP + $\mathrm{CaCl}_{2}$ medium (closed circles). Cell densities were standardized at $3 \times 10^{7} \mathrm{CFU} \mathrm{ml}$ ${ }^{1}$ (part a), $3 \times 10^{8} \mathrm{CFU} \mathrm{ml}^{-1}$ (part b) and $3 \times 10^{9} \mathrm{CFU} \mathrm{ml}^{-1}$ (part c). Control cultures (open circles) were added with an extract prepared from the un-inoculated TYEP + $\mathrm{CaCl}_{2}$ medium. The means are representative of three independent experiments. 
The relationship between QS and food spoilage depends on the strain under study and highlights the complexity of food environments. In Serratia proteamaculans B5A, the synthesis of proteases and lipases related to milk spoilage was shown to be regulated by cell density (3). However, the proteolytic activity and production of signal molecules in Aeromonas hydrophila aroA, for example, were affected by media composition and aeration, and AHL concentration did not correlate with protease production (24). Furthermore, wild type cultures of Hafnia alvei spoiled meat at the same rate as an AHL-deficient mutant (2).

In conclusion, $P$. fluorescens 07A did not appear to produce AHL molecules, emphasizing that AHL detection solely by bioassay strains might lead to false positive results.

\section{ACKNOWLEDGEMENTS}

We thank Dr. Anatol Eberhard for the GC/MS analyses, and Dr. Stephen C. Winans for the monitor strains. UM Pinto and ED Costa were supported by Conselho Nacional de Pesquisa e Desenvolvimento-CNPq, Coordernadoria de Pessoal de Nível Superior-Capes (Brazil) and National Institute of General Medical Sciences (GM41892).

\section{REFERENCES}

1. Allison, D.G.; Ruiz, R.; Sanjose, C.; Jaspe, A.; Gilbert, P. (1998) Extracellular products as mediators of the formation and detachment of Pseudomonas fluorescens biofilms. FEMS Microbiol. Lett., 167, 179184.

2. Bruhn, J.B.; Christensen, A.B.; Flodgaard, L.R.; Nielsen, K.F.; Larsen, T.; Givskov, M.; Gram, L. (2004). Presence of acylated homoserine lactones (AHLs) and AHL-producing bacteria in meat and potential role of AHL in spoilage of meat. Appl. Environ. Microbiol., 70, 4293-4302.

3. Christensen, A.B.; Riedel, K.; Eberl, L.; Flodgaard, L.R.; Molin, S.; Gram, L.; Givskov, M. (2003). Quorum-sensing-directed protein expression in Serratia proteamaculans B5a. Microbiol., 149, 471-483.

4. Dogan, B.; Boor, K.J. (2003). Genetic diversity and spoilage potentials among Pseudomonas spp. isolated from fluid milk products and dairy processing plants. Appl. Environ. Microbiol., 69, 130-138.

5. Gram, L.; Christensen, A.B.; Ravn, L.; Molin, S.; Givskov, M. (1999). Production of acylated homoserine lactones by psychrotrophic members of the Enterobacteriaceae isolated from foods. Appl. Environ. Microbiol., 65, 3458-3463.
6. Gram, L.; Ravn, L.; Rasch, M.; Bruhn, J.B.; Christensen, A.B.; Givskov, M. (2002). Food spoilage - interactions between food spoilage bacteria. Int. J. Food Microbiol., 78, 79-97.

7. Holden, M.T.G.; Chhabra, S.R.; Nys, R.; Stead, P.; Bainton, N.J.; Hill, P.J.; Manefield, M., Kumar, N.; Labatte, M.; England, D.; Rice, S.; Givskov, M.; Salmond, G.P.C.; Stewart, G.S.A.B.; Bycroft, B.W.; Kjelleberg, S.; Williams, P. (1999). Quorum sensing crosstalk: isolation and chemical characterization of cyclic dipeptides from Pseudomonas aeruginosa and other gram-negative bacteria. Mol. Microbiol., 33, 12541266.

8. Khan, S.R.; Mavrodi, D.V.; Jog, G.J.; Suga, H.; Thomashow, L.S.; Farrand, S.K. (2005). Activation of the phz operon of Pseudomonas fluorescens 2-79 requires the LuxR homolog PhzR, N-(3-OH-hexanoyl)L-homoserine lactone produced by the LuxI homolog PhzI, and a cisacting phz box. J. Bacteriol., 187 (18), 6517-6527.

9. Liao, C.; Mccallus, D.E. (1998). Biochemical and genetic characterization of an extracellular protease from Pseudomonas fluorescens CY091. Appl. Environ. Microbiol., 64, 914-921.

10. Liu, M.; Wang, H.; Griffiths, M.W. (2007). Regulation of alkaline metalloprotease promoter by $\mathrm{N}$-acyl homoserine lactone quorum sensing in Pseudomonas fluorescens. J. Appl. Microbiol., 103 (6), 2174-2184.

11. Malik, R.K.; Prasad, R.; Mathur, D.K. (1985). Effect of some nutritional and environmental factors on extracellular protease production by Pseudomonas sp. B-25. Lait, 65, 169-183.

12. Martins, M.L. (2007). Characterization of protease and lipase from Pseudomonas fluorescens and quorum sensing in psychrotrophic bacteria isolated from milk. Viçosa, MG. UFV. (DSc thesis in Agricultural Microbiology), Universidade Federal de Viçosa.

13. Martins, M.L.; Araújo, E.F.; Mantovani, H.C.; Moraes, C.A.; Vanetti, M.C.D. (2005). Detection of the apr gene in proteolytic psychrotrophic bacteria isolated from refrigerated raw milk. Int. J. Food Microbiol., 102, 203-211.

14. Matselis, E.; Roussis, I.G. (1998). Proteinase and lipase production by Pseudomonas fluorescens. Proteolysis and lipolysis in thermized ewe's milk. Food Control, 9, 251-259.

15. Miller, J. (1972). Experiments in molecular genetics. Cold Spring Harbor Laboratory Press, Cold Spring Harbor, New York.

16. Morton, R.D. (2001). Aerobic plate count. In: Downes, F.P., Ito, K, Compendium of methods for the microbiological examination of foods, (4rd ed), (pp.63-67) Washington DC: American Public Health Association.

17. Pinto, U.M.; Viana, E.S.; Martins, M.L.; Vanetti, M.C.D. (2007). Detection of acylated homoserine lactones in gram-negative proteolytic psychrotrophic bacteria isolated from cooled raw milk. Food Control, 18 (10), 1322-1327.

18. Rajmohan, S.; Dodd, C.E.R.; Waites, W.M. (2002). Enzymes from isolates of Pseudomonas fluorescens involved in food spoilage. J. Appl. Microbiol., 93, 205-213. 
Pinto, U.M. et al.

19. Ravn, L.; Christensen, A.B.; Molin, S.; Givskov, M.; Gram, L. (2001). Methods for detecting acylated homoserine lactones produced by gramnegative bacteria and their application in studies of AHL-production kinetics. J. Microbiol. Meth., 44, 239-251.

20. Shaw, P.D.; Ping, G.; Daly, S.L.; Chung, C.; Cronan, J.E.; Rinehart, K.L.; Farrand, S.K. (1997). Detection and characterizing N-acilhomoserine lactone signal molecules by thin-layer chromatography. Proc. Natl. Acad. Sci. USA, 94, 6036-6041.

21. Siddiqui, I.A.; Haas, D.; Heeb, S. (2005). Extracellular protease of Pseudomonas fluorescens $\mathrm{CHA}$, a biocontrol factor with activity against the root-knot nematode Meloidogyne incognita. Appl. Environ. Microbiol., 71, 5646-5649.

22. Smith, J.L.; Fratamico, P.M.; Novak, J.S. (2004). Quorum sensing: a primer for food microbiologists. J. Food Prot., 67, 1053-1070.

23. Sørhaug, T.; Stepaniak, L. (1997). Psychrotrophs and their enzymes in milk and dairy products: quality aspects. Trends Food Sci. Technol., 8,
$35-40$.

24. Vivas, J.; Razquin, B.E.; López-Fierro, P. Naharro, G.; Villena, A. (2004). Correlation between production of acyl homoserine lactones and proteases in an Aeromonas hydrophila aroA live vaccine. Vet. Microbiol., 101, 167-176.

25. Whan, L.; Dunstall, G.; Rowe, M.T. (2000). A study of the growth kinetics of two pseudomonads from pasteurized milk and the possible role of quorum sensing. Milchwissenschaft, 55, 371-373.

26. Whitehead, N.A.; Barnard, A.M.L.; Slater, H. Simpson, N.J.L.; Salmond, G.P.C. (2001). Quorum-sensing in gram-negative bacteria. FEMS Microbiol. Rev., 25, 365-404.

27. Zhu, J.; Chai, Y.; Zhong, Z.; Li, S.; Winans, S.C. (2003). Agrobacterium bioassay strain for ultrasensitive detection of $\mathrm{N}$-acylhomoserine lactonetype quorum-sensing molecules: detection of autoinducers in Mesorhizobium huakuii. Appl. Environ. Microbiol., 69, 6949-6953. 